Int. J. Adv. Eng. Pure Sci. 2020, I: 96-1 10

DOI: 10.7240/jeps.581959

RESEARCH ARTICLE / ARAŞTIRMA MAKALESI

\title{
Ağsız Yöntem Uygulamaları için Trigonometri Tabanlı Radyal Özelliğe Sahip Yeni Bir Temel Fonksiyon
}

\author{
A New Trigonometric Based Radial Basis Function for Meshless Method Applications
}

\author{
Atakan ALTINKAYNAK ${ }^{1}$ \\ ${ }^{1}$ İstanbul Teknik Üniversitesi, Makina Fakültesi, Makina Mühendisliği Bölümü, 34437, Beyoğlu, İstanbul, Türkiye
}

Öz

Bu çalışmada, ağsız yöntemler için radyal özelliğe sahip yeni bir temel fonksiyon önerilmiştir. Önerilen fonksiyon, iki boyutta, dört farklı problemde, ağsız yöntemlerde sıklıkla kullanılan Ters Multikuadrik ve Gauss fonksiyonlarıyla birlikte test edilmiştir. Test problemlerinin üç tanesi 2. mertebeden mühendislik problemlerini içerirken son test problemi 4. mertebeden bir mühendislik problemi uygulaması olmuştur. 2. mertebeden test problemlerinde farklı sınır koşulları ve problem türleri incelenmiştir. Yapılan sayısal deneyler, önerilen fonksiyonun Ters Multikuadrik ve Gauss fonksiyonlarına kıyasla daha az nokta sayılarında benzer mertebedeki hatalara ulaşabildiğini göstermiştir. Ayrıca nokta sayısının artmasıyla aynı mertebedeki hatalar için kullanılabilecek şekil/ölçek parametresinin $(\epsilon)$ diğer iki fonksiyona kıyasla daha geniş bir aralıkta seçilebildiği gösterilmiştir. Dolayısıyla, önerilen fonksiyon, ağsız yöntem uygulamalarında bir alternatif olarak kullanılabilecektir.

Anahtar Kelimeler: Radyal özelliğe sahip temel fonksiyon, trigonometri, ağsız yöntemler, Multikuadrik, Gauss

\begin{abstract}
In this study, a new radial basis function for meshless method is proposed. The proposed function was tested on four different 2D problems along with the two well-known IMQ and Gauss functions. Three of the test problems include $2^{\text {nd }}$ order engineering problems whereas the last test problem was a $4^{\text {th }}$ order engineering problem. $2^{\text {nd }}$ order engineering problems were used to investigate the type of boundary conditions and problems. Numerical experiments suggested that similar order of error can be obtained using the proposed function with less number of nodes compared to IMQ and Gauss functions. Besides that, with an increase on the number of nodes, the range of shape/scale parameter $(\epsilon)$ for the proposed function is broader that that for the other two functions. Thus, the proposed function is a good candidate for meshless method applications.
\end{abstract}

Keywords: Radial basis function, trigonometry, meshless methods, Multiquadric, Gauss

\section{GİRIS}

Günümüzde mühendislik problemlerinin sayısal çözümünde Sonlu Elemanlar Yöntemi [1], Sonlu Hacimler Yöntemi [2], Sınır Elemanlar Yöntemi [3], Ağsız Yöntemler [4] gibi farklı araçlar kullanılmaktadır. Özellikle son 30 yıldır süren yoğun geliştirmeler sonucunda, Sonlu Elemanlar Yöntemi artık diferansiyel denklem çözümlerinde standart olarak kullanılan bir yöntem halini almıştır [5]. Bunun yanı sıra, bir ağ yapısı gerektirmemesi ve çok sayıda bağımsız değişkenli problemler için kolaylıkla uygulanabilir olması, ağsız yöntemlerin uygulama alanını gün geçtikçe genişletmektedir. Ağsız yöntemlerin bir kolu olan radyal özelliğe sahip temel fonksiyonlar (RTF), son yıllarda öne çıkan yöntemlerden birisidir [5]. RTF fonksiyonların iki temel özelliği olan fonksiyon merkezinden eşit uzaklıkta fonksiyonun aynı değeri alması (radyal) ve fonksiyonun her derecede türevinin olması, bu fonksiyonların uygulama alanını genişletmiştir. İlk olarak Kansa [6, 7], Multikuadrik RTF fonksiyonunu diferansiyel denklemlerin çözümünde kullanarak RTF ağsız yöntemlerin mühendislik uygulamalarında 
kullanılmasının önünü açmıştır. Günümüzde Gauss, Ters Multikuadrik, Bessel ve Wendland gibi çok farklı RTF fonksiyonlarının mühendislik problemlerine uygulamaları mevcuttur [8].

Diferansiyel denklemlerin çözümünde RTF kullanılarak üssel yakınsama hızları elde edilebilmiştir [9]. Fakat burada önemli olan hususlardan biri, RTF'yi oluşturan ve genelde $\epsilon$ ile tanımlanan şekil/ölçek parametresinin optimum değerinin belirlenmesidir. Şekil parametresinin küçük değerleri için daha kesin sonuçlar elde edilebilirken bu değerdeki düşüş çözümde sayısal kararsızlıklara ve ıraksamalara neden olmaktadır [10]. Bu kararsızlıkların giderilmesinde Contour-Pade [11] ve RBF-QR [12] gibi temel değişiklikler gerektiren yöntemler dışında, matris değişikliği içeren ön koşullandırma (preconditioning) [13] ve noktalar arası ilişkinin tüm çözüm bölgesi yerine yerel bir bölge için tanımlanması (local support) [14] gibi yöntemler geliştirilmiştir. Optimum $\epsilon$ değeri, problemin ve kullanılan RTF'nin türünden, sınır koşullarından, nokta dağılımından ve nokta sayısından oldukça etkilenmektedir. Dolayısıyla, optimum $\epsilon$ değerinin belirlenmesi günümüzde üzerinde araştırma yapılan konulardan biridir [15-17].

Yapılan çalışmalarda her ne kadar çok sayıda RTF geliştirilmiş olsa da, literatürde trigonometrik fonksiyon temelli bir RTF'ye rastlanılmamıştır. Yapılan çalışmada, trigonometrik fonksiyon temelli yeni bir RTF ortaya konmuştur. Bu RTF, 2-boyutta, dört farklı problemde ve farklı sınır koşullarında kullanılarak çözümler elde edilmiştir. Bu çözümler, Gauss ve Multikuadrik RTF çözümleri ile kıyaslanarak geliştirilen RTF’nin karakteristik özellikleri belirlenmiştir.

\section{SAYISAL YÖNTEM}

\subsection{Noktasal RTF Yöntemi}

Genel bir kısmi diferansiyel denklem Eşitlik (1) ve (2)'deki gibi verilebilir:

$$
\begin{array}{cc}
\mathcal{L} \phi=f(\boldsymbol{x}) & \boldsymbol{x} \in \Omega, \\
\mathcal{B} \phi=g(\boldsymbol{x}) & \boldsymbol{x} \in \partial \Omega
\end{array}
$$

$\mathrm{Bu}$ denklemlerde $\mathcal{L}$ diferansiyel operatörünü, $\mathcal{B}$ Dirichlet, Neumann gibi sınır koşulları operatörünü, $\Omega$ çözüm bölgesini, $\partial \Omega$ ise çözüm bölgesi sınırlarını ifade etmektedir. Noktasal RTF yönteminde, diferansiyel denklemde çözülmeye çalışılan bağımsız bilinmeyen $\phi$ 'nin $\boldsymbol{x}_{\boldsymbol{i}}$ noktasındaki değeri, RTF'nin bu nokta temel alındığında, diğer tüm merkez noktadaki değerlerinin doğrusal kombinasyonu olarak Eşitlik (3) ve (4)'teki gibi yazılabilir:

$$
\begin{aligned}
\phi\left(\boldsymbol{x}_{\boldsymbol{i}}\right) & =\sum_{j=1}^{N_{c}} c_{j} \varphi_{j}\left(x_{i}\right) \\
\phi^{\prime}\left(\boldsymbol{x}_{\boldsymbol{i}}\right) & =\sum_{j=1}^{N_{c}} c_{j} \varphi_{j}^{\prime}\left(x_{i}\right)
\end{aligned}
$$

Bu denklemlerde; $\boldsymbol{x}_{\boldsymbol{i}^{\prime}}, i^{\prime}$ ninci çözüm bölgesi noktasını, $N_{c}$, merkez nokta sayısını, $\varphi(\boldsymbol{x})$, RTF'yi, $c$ ise $\phi, \phi^{\prime}, \ldots$ gibi bağımsız bilinmeyen fonksiyonların yaklaşık değerinin belirlenebilmesi için hesaplanması gereken sabitleri ifade etmektedir. Eşitlik (3) ve (4)'ten görülebileceği gibi, $c$ katsayıları sabit olduğundan dolayı $\phi^{\prime}$ nın $n$. mertebeden türevinin yaklaşı değerinin belirlenebilmesi için RTF fonksiyonunun $n$. mertebeden türevinin kullanılması gerekmektedir. RTF fonksiyonlarının her dereceden türevleri bulunduğundan dolayı bu işlem rahatlıkla yapılabilmektedir. Eşitlik (3) ve (4)'teki denklemler, Eşitlik (1) ve (2)'deki diferansiyel denklem ve sınır koşulları denklemlerinde yerine konulduğunda noktasal yaklaşı çözüm için gerekli olan $c$ sabitleri Eşitlik (5) kullanılarak elde edilebilir:

$$
\underbrace{\left[\begin{array}{l}
\mathcal{L} \phi(\boldsymbol{x}) \\
B \phi(\boldsymbol{x})
\end{array}\right]}_{A}\{c\}=\{0\}
$$

c sabitleri belirlendikten sonra Eşitlik (3)'te yerine konularak yaklaşık çözüm elde edilmektedir. Eşitlik (5)'in çözülebilmesi için $A \neq 0$ olması gerekmektedir. RTF kullanılması durumunda, $A$ matrisi pozitif tanımlı matris olmaktadır ve bu durum da bir çözüm elde edilebileceğini göstermektedir. Fakat burada dikkat edilmesi gereken durum; problem türü, sınır koşulları, RTF türü, nokta dağılımı, nokta sayısı, çözüm bölgesi noktalarının etkileşimde olduğu merkez noktası sayısı vb. etkenlerin $A$ matrisinin karakteristiğini etkileyerek matrisin determinantının sıfıra yaklaşmasına neden olmasıdır (kötü koşullanma -ill conditioning). Bu durum da çözümde kararsızlıklar ortaya çıkarmaktadır.

Diferansiyel denklem çözümlerinde sıkça kullanılan RTF örnekleri Tablo 1'de verilmektedir. Tablo 1'de $r=\|x-y\|_{2}$, çözüm bölgesi noktaları ile merkez noktaları arasındaki mesafeyi, $\varepsilon$, şekil/ölçek parametresini, $K$, ikinci türden değiştirilmiş Bessel fonksiyonunu ve $d$ boyutu ifade etmektedir. Genel Multikuadrik fonksiyonunda $\beta$ değerinin negatif olduğu durumda fonksiyon Ters Multikuadrik, pozitif olduğu durumda ise Multikuadrik olarak adlandırılmaktadır. Çözüm bölgesi noktaları, çözüm bölgesi içinde ve sınırlarında olabilirken, merkez noktaları, çözüm bölgesi dışında da olabilmektedir. Uygulamalarda, çözüm bölgesi sınırındaki noktalar için belirlenen merkez noktalarının, çözüm bölgesi dışında olması durumunda hatanın azaldığı gözlemlenmiştir 
[18]. Bu bulgu henüz herhangi bir teoriye dayanmadığından dolayı, genelde yapılan çalışmalarda merkez noktaları, çözüm bölgesi noktaları ile aynı koordinatlarda seçilmektedir [5].

Nokta sayısı ve dağılımının $A$ matrisinin karakteristiğini etkilediğinden bahsedilmişti. Literatürde düzgün, Halton, Chebyshev, Glacier, Optimal gibi çok sayıda nokta dağılımı yöntemi bulunmaktadır [10]. Örnek olarak, düzgün ve Halton nokta dağılımı Şekil 1'de verilmektedir. Halton nokta dağılımı durumunda, noktalar çözüm bölgesi içerisinde düzgünvari şekilde rastgele olarak dağılmaktadırlar. Bu durumda, tamamen rastgele duruma göre daha kesin sonuçlar elde edilmektedir [19]. Şekil 1'de sadece çözüm bölgesi noktaları gösterilmekte, merkez noktaları ise gösterilmemektedir. Yapılan çalışmada, merkez noktaları, çözüm bölgesi noktalarıyla aynı koordinatlarda seçilmiştir.

Tablo 1. Diferansiyel denklem çözümlerinde kullanılan RTF örnekleri

\begin{tabular}{ccc}
\hline İsim & Formül $\varphi(x)$ & \\
\hline Gauss & $e^{-(\varepsilon r)^{2}}$ & $\varepsilon>0$ \\
$\begin{array}{c}\text { Genel Multi- } \\
\text { kuadrik }\end{array}$ & $\left(1+(\varepsilon r)^{2}\right)^{\beta}$ & $\varepsilon>0, \quad \beta \in \mathbb{R} \backslash \mathbb{N}_{0}$ \\
Matern & $\frac{K_{\frac{d}{2}-\beta}(\varepsilon r)}{(\varepsilon r)^{\frac{d}{2}-\beta}}$ & $\varepsilon>0, \quad \beta>\frac{d}{2}$ \\
\hline
\end{tabular}

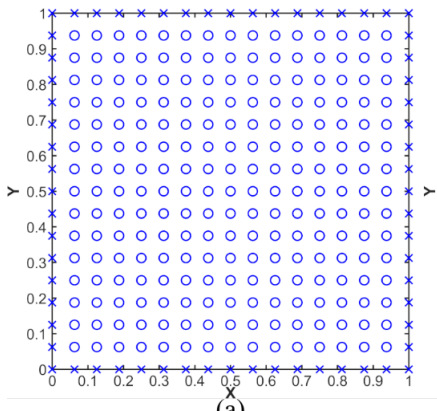

(a)

Şekil 1. Çözüm bölgesi içerisinde (o) ve sınırlarındaki (x) örnek nokta dağılımı (289 adet nokta için): (a) Düzgün dağılım, (b)

Halton dağılımı

$$
\varphi(\boldsymbol{x})= \begin{cases}\frac{\sin (\varepsilon r)}{\varepsilon r} & , r>0 \\ 1 & , r=0\end{cases}
$$

Sinüs-RTF fonksiyonunun $(x, y) \in[0,1]^{2}$ çözüm bölgesi içerisinde $(0,5,0,5)$ noktası için davranışı Şekil 2'de verilmektedir. $\varepsilon$ parametresinin değeri azaldıkça Gauss ve Ters Multikuadrik RTF'de olduğu gibi Sinüs-RTF de yataya yakın bir fonksiyon halini almakta ve bu durum $A$ matrisinin kötü koşullanmasına neden olmaktadır. $\varepsilon$ değeri arttıkça farklı RTF'ler farklı karakteristik göstermektedir. Fakat genel olarak $\varepsilon$ değeri arttıkça çözüm kararlılığı artmakla birlikte hata miktarı da artmaktadır. Dolayısıyla, optimum bir $\varepsilon$ değerinin belirlenmesi gerekmektedir. $\varepsilon$ değeri arttıkça Gauss ve Ters Multikuadrik fonksiyonların davranışı, çözüm noktası civarında sivri bir tepe ve diğer kısımlarda sıfıra yakın yatay bir davranış şeklinde olurken, Sinüs-RTF'in davranışı sivri tepe dışındaki kısımlarda fonksiyon tanımı itibariyle salınım şeklindedir (Şekil 2). Ayrıca, Sinüs-RTF’nin radyal karakteristiği Şekil 2'de gözükmektedir.

Sinüs-RTF fonksiyonunun parçalı fonksiyon olarak tanımlanmasının nedeni, $\frac{\sin (\varepsilon r)}{\varepsilon r}$ teriminin $r=0^{\prime}$ da tanımsız olmasıdır. Çözüm bölgesi ile merkez noktasının aynı olduğu durumlarda $r=0$ olmakta ve $\frac{\sin (\varepsilon r)}{\varepsilon r}$ terimi tanımsız olmaktadır. Bu durumda bir çözüm elde edilememektedir. $r=0$ dışındaki (çözüm bölgesi ve merkez noktalarının farklı koordinatlarda olma durumu) tüm reel sayılar için ise bu fonksiyon tanımlı ve süreklidir. Bu tür süreksizlikler, kaldırılabilir süreksizlik olarak ifade edilmekte ve fonksiyonun tanımlı olmadığ1 noktalarda fonksiyonun limit değeri kullanılarak giderilebilmektedir. Bu sebepten dolayı, Sinüs-RTF fonksiyonu parçalı fonksiyon olarak tanımlanarak $r=0$ için Eşitlik (7)'de verilen limit değeri kullanılmıştır. Böylece fonksiyon sürekli hale getirilmiştir. Benzer şekilde, Sinüs-RTF'nin farklı mertebelerdeki türevlerinin de diferansiyel denklem çözümlerinde $r=0$ için tanımlanması gerekmektedir. Örnek olarak, Sinüs-RTF'nin, Laplace problemi için tanımı Eşitlik (8)'deki gibi olmaktadır. Benzer RTF, kosinüs fonksiyonu kullanılarak elde edilememektedir çünkü kosinüs fonksiyonunun $r \rightarrow 0$ durumu için limiti bulunmamaktadır.

$$
\lim _{r \rightarrow 0} \frac{\sin (\varepsilon r)}{\varepsilon r}=1
$$

$\nabla^{2} \varphi(\boldsymbol{x})= \begin{cases}\frac{\sin (\varepsilon r)-\varepsilon r(\cos (\varepsilon r)+\varepsilon r \sin (\varepsilon r))}{\varepsilon r^{3}} & , r>0 \\ -\frac{2 \varepsilon^{2}}{3} & , r=0\end{cases}$
Yapılan çalışmada trigonometrik fonksiyon temelli yeni bir RTF fonksiyonu oluşturulmuştur. Bu fonksiyon Eşitlik (6)'da verilmektedir. 


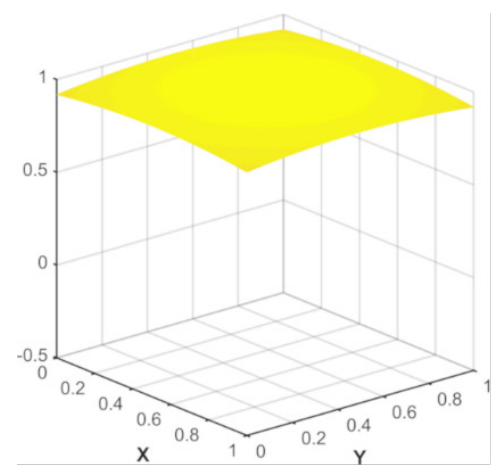

(a)

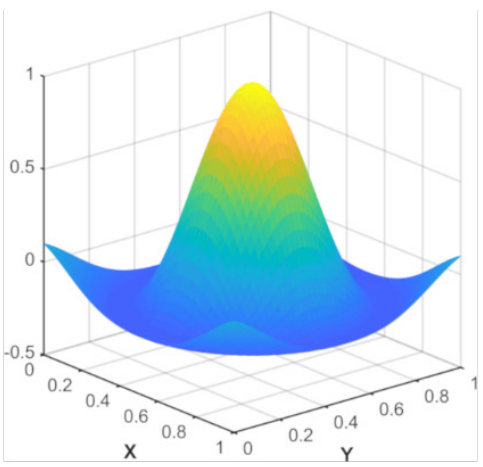

(b)

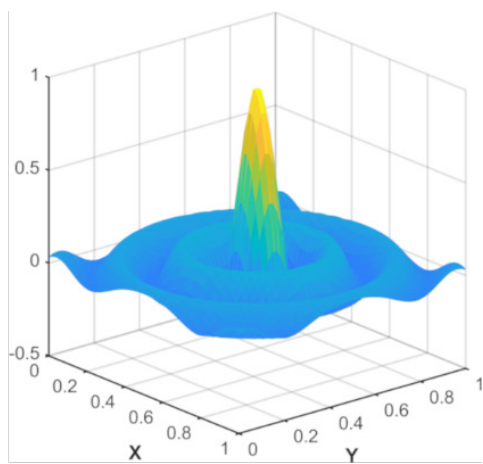

(c)

Şekil 2. Sinüs-RTF fonksiyonunun $(0,5,0,5)$ noktası için $[0,1]^{2}$ çözüm bölgesi içerisinde davranış1: (a) $\varepsilon=1$, (b) $\varepsilon=10$, (c) $\varepsilon=30$

\section{SAYISAL DENEYLER ve TARTIŞMALAR}

Önerilmiş olan radyal özelliğe sahip temel fonksiyon Sinüs-RTF'nin davranışı, farklı sayısal problemler için test edilmiştir. $\mathrm{Bu}$ bölümde seçilen problemler, mühendislik problemlerinde sıklıkla karşılaşılan 2-boyutlu eliptik diferansiyel denklemlerden oluşmaktadır. Problemlerin belirlenmesinde analitik çözümün olmasına dikkat edilmiş, böylece hatanın hassas bir şekilde belirlenebilmesi amaçlanmıştır. Problemlerde çözüm bölgesinin $(x, y) \in \Omega=[0,1]^{2}$ olduğu kabul edilmiştir. Çözümler, düzgün ve Halton nokta dağılımı durumunda ve farklı nokta sayıları için elde edilmiştir. Çözüm bölgesinde hatayı belirlemek için düzgün olarak dağılmış 40×40 değerlendirme noktasında, analitik çözüm ile sayısal çözümler karşılaştırılarak karesel hata (RMS) ve maksimum hata değerleri elde edilmiştir. Karesel hata değeri Eşitlik (9) kullanılarak hesaplanmıştır.

$$
R M S=\sqrt{\frac{\sum_{i=1}^{n}\left(\mathbf{x}_{\text {analitik }}-\mathbf{x}_{\text {saylsal }}\right)_{i}^{2}}{n}}
$$

Eşitlik (9)'da $n$ çözüm bölgesinde bulunan toplam nokta sayısını ifade etmektedir.

Temel olarak, Eşitlik (1)'deki $\mathcal{L}$ operatörü, değişken katsayılara sahip eliptik bir operatör olarak Eşitlik (10)'daki gibi tanımlanabilir. Eşitlik (10), iki boyutta süreksiz (heterojen) ve yöne bağlı (anisotropik) ortamlardaki sızıntı akışı mühendislik problemine karşıllk gelmektedir.

$$
\frac{\partial}{\partial x}\left[a(x, y) \frac{\partial \phi}{\partial x}\right]+\frac{\partial}{\partial y}\left[b(x, y) \frac{\partial \phi}{\partial y}\right]=f(x, y)
$$

Eşitlik (10)'da $a(x, y)=1$ ve $b(x, y)=1$ olarak seçilmesi durumunda, standart Poisson problemi elde edilmektedir. Poisson problemi mühendislikte elektrostatik, 1s1 transferi, akışkanlar mekaniği, difüzyon problemleri gibi birçok alanda karşımıza çıkmaktadır. Dolayısıyla, ilk aşamada farklı sınır koşulları için Poisson problemi, önerilen Sinüs-RTF kullanılarak çözülmüştür. Sayısal sonuçlar, Gauss ve IMQ $(\beta=-0,5)$ RTF'leri kullanılarak elde edilen sonuçlar ile karşılaştırılmıştır. Böylece, farklı RTF'lerin bu problemlerdeki davranışları hakkında bilgi sahibi olunmuştur.

\subsection{Poisson Problemi-1}

İlk Poisson problemi, Dirichlet sınır koşullarına sahiptir ve Eşitlik (11)'deki gibi tanımlanmıştır [20].

$$
\begin{gathered}
\nabla^{2} \phi(x, y)=-\frac{5 \pi^{2}}{4} \sin (\pi x) \cos \left(\frac{\pi y}{2}\right), \\
\phi(x, y)=\sin (\pi x), \quad(x, y) \in \Gamma_{1}, \\
\phi(x, y)=0, \quad(x, y) \in \Gamma_{2}, \\
\Gamma_{1}=\{(x, y): 0 \leq x \leq 1, y=0\}, \Gamma_{2}=\partial \Omega \backslash \Gamma_{1}
\end{gathered}
$$

Eşitlik (11)'den görüldüğü gibi, bu problemde $y=0$ olan sınır için $\phi(x, y)=\sin (\pi x)$ ve diğer sınırlar için ise $\phi(x, y)=0$ Dirichlet sınır koşulları tanımlanmıştır. $\mathrm{Bu}$ problemin analitik çözümü

$$
\phi(x, y)=\sin (\pi x) \cos \left(\frac{\pi y}{2}\right)
$$

olarak elde edilmektedir. Bu problemde; farklı $\epsilon$ değerleri için Sinüs-RTF, Multikuadrik ve Gauss RTF kullanılarak elde edilen karesel hata (RMS) değerleri Şekil 3'de verilmektedir. Şekil 3'ten görülebileceği gibi, en düşük karesel hatanın elde edildiği $\epsilon$ değerini RTF türünün yanı sıra nokta sayısı ve nokta dağılımı da etkilemektedir. Ayrıca, sayısal yöntemin kararlı$\operatorname{lığ}_{1} \epsilon$ değerinden oldukça etkilenmektedir. Bu durum, daha önceki yapılan çalışmalarda belirtilmiştir [5, 21]. Nokta sayısının artması ve $\epsilon$ değerinin azalması (fonksiyonun düz yatay çizgiye yaklaşması), $A$ matrisinin kötü koşullanmasına neden olarak Şekil 3’te görülen kararsızlıkları oluşturmaktadır. Bu kararsızlıkların giderilmesinde kullanılan farklı yöntemlerden "Giriş" bölümünde bahsedilmiştir. Ayrıca, Şekil 3 'teki sonuçlara bakıldığında, Sinüs-RTF için $10^{-6}$ 'dan daha düşük hata değerlerinin elde edildiği $\epsilon$ aralığının, diğer iki RTF'e göre daha geniş olduğu görülmektedir. Bu durumun, özellikle en uygun $\epsilon$ parametresinin belirlenmesinde avantaj sağlayacağ düşünülmektedir. 


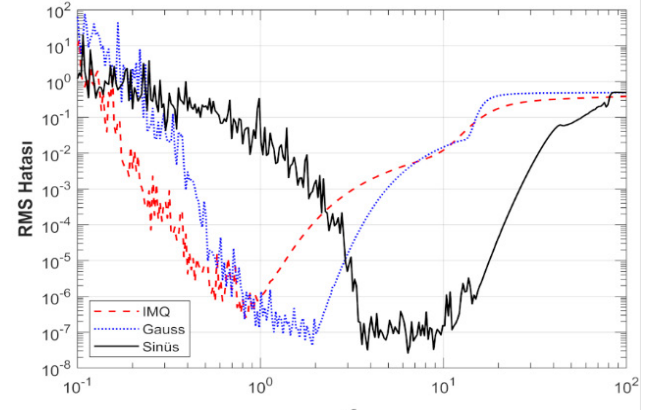

(a)

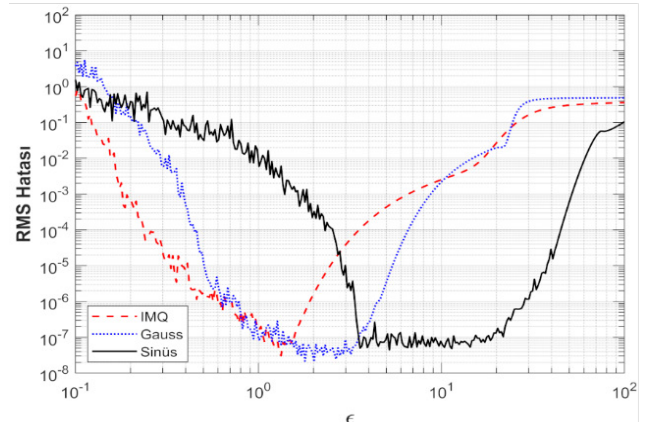

(c)

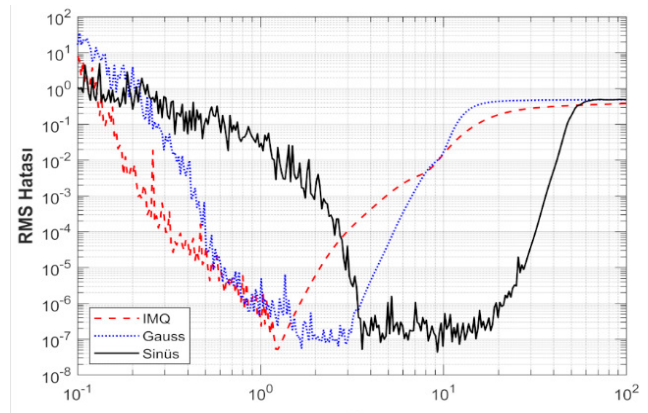

(b)

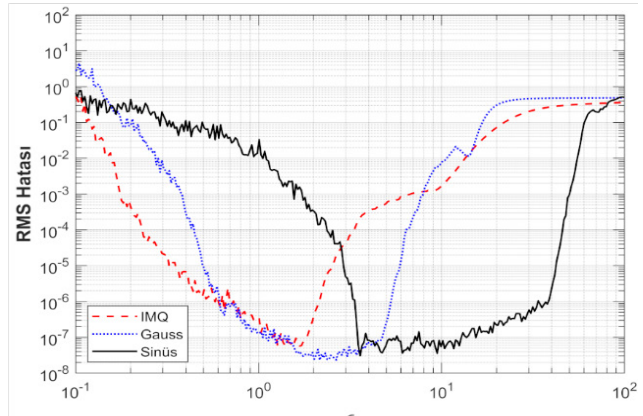

(d)

Şekil 3. Farklı nokta dağılımı ve nokta sayısı için $\epsilon$ parametresine göre karesel hatanın değişimi: (a) 225 nokta düzgün dağılım, (b) 625 nokta düzgün dağılım, (c) 225 nokta Halton dağılımı, (d) 625 nokta Halton dağılımı

Şekil 4'te karesel hatanın, sabit $\epsilon$ parametresi için nokta sayısına bağlı olarak değişimi gösterilmiştir. IMQ, Gauss ve Sinüs RTF'ler için sırasıyla $\epsilon=1, \epsilon=2$ ve $\epsilon=4$ olarak alınmıştır. Nokta sayısı düzgün dağılım için 100 'e, Halton dağılım için ise 50'ye kadar arttıkça, Sinüs-RTF kullanılarak elde edilen karesel hata, diğer iki RTF'ye göre daha hızlı bir şekilde azalmaktadır. Nokta sayısı daha fazla arttığında ise hata kararsız ve genel olarak yatay bir seyir izlemiştir. Bu durumun nedeni, nokta sayısının daha fazla artmasıyla $A$ matrisinin boyutunun büyüyerek kötü koşullanmasıdır. IMQ ve Gauss RTF'lerinde daha fazla nokta sayısı için kararlı sonuçlar elde edilerek hatanın azaltılması sağlanabilmektedir. Sinüs-RTF ile 80 nokta kullanılarak elde edilen hata mertebelerine IMQ ve Gauss RTF'lerinde 200 ve daha fazla nokta kullanıldığı durumda ulaşılmaktadır. Dolayısıyla, Sinüs-RTF kullanılması durumunda benzer hata mertebelerine daha az nokta kullanılarak erişilebildiği gözlemlenmiştir.

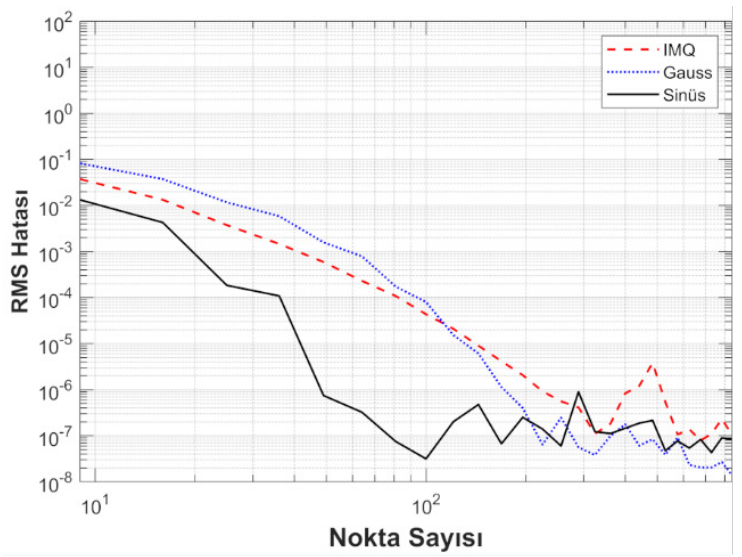

(a)

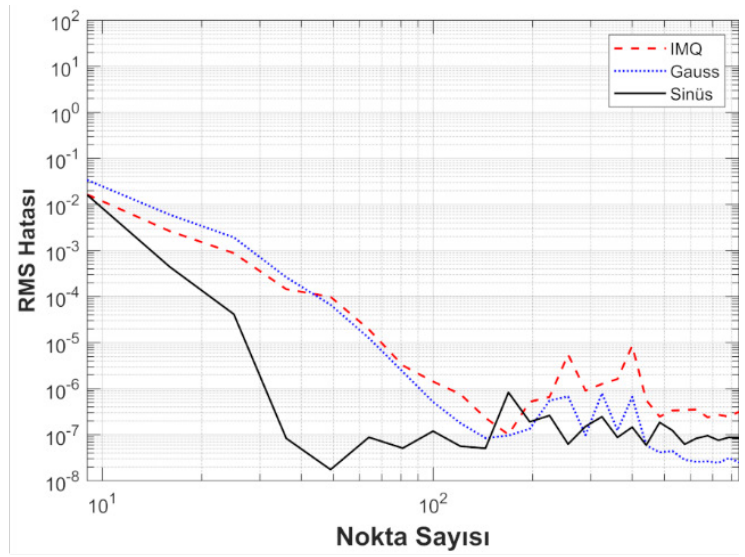

(b)

Şekil 4. Farklı nokta dağılımı ve nokta sayısı için karesel hatanın değişimi: (a) Düzgün nokta dağılımı, (b) Halton nokta dağglımı 
Hatanın çözüm bölgesindeki davranışı Halton ve düzgün nokta dağglımı durumunda incelenen tüm RTF'ler için Şekil 5 'te verilmiştir. Sonuçlar, 81 nokta için elde edilen değerlerdir ve sonuçların daha iyi yorumlanabilmesi için renk aralıkları her bir durum için elde edilen maksimum hataya göre belirlenmiştir. IMQ, Gauss ve Sinüs-RTF'ler için $\epsilon$ değerleri sırasiyla $\epsilon=1, \epsilon=2$ ve $\epsilon=4$ olarak sabit tutulmuştur. IMQ ve Gauss RTF'lerin kullanıldığı durumda Halton nokta dağılımı, düzgün nokta dağılımına göre daha az hata oluşmasını sağlamıştır. Ayrıca düzgün nokta dağılımında hata genelde sınırlara yakın artış gösterirken, Halton nokta dağılımında bu davranış köşelere yakın gözlemlenmiştir. Sinüs-RTF kullanılması durumunda her iki nokta dağılımı için IMQ ve Gauss RTF'den daha düşük hata elde edilmiştir. Düzgün ve Halton nokta dağılımında ise diğer iki RTF'nin aksine hata mertebeleri birbirine yakındır. Hatanın genel davranışı incelendiğinde, Sinüs-RTF kullanıldığı durumda hatanın sınırlarda yoğunlaşmadığı, aksine tüm çözüm bölgesine dağılarak tepecikler şeklinde oluştuğu gözlemlenmiştir. $\mathrm{Bu}$ davranışın elde edilmesindeki en büyük etkenin, her bir nokta için RTF fonksiyonunun çözüm bölgesinde gösterdiği davranış olduğu söylenebilir. Bu sebepten dolayı, aynı $\epsilon$ değeri kullanıldığı durumda, Sinus-RTF'de nokta sayısı belli bir değerin üstüne çıktığında hatada fazla bir değişim gözükmemektedir. Gauss ve IMQ RTF için ise nokta sayısındaki artış, köşe ve kenardaki hataların azalmasını sağlayarak genel hatanın düşme eğilimine girmesini sağlamıştır.

\subsection{Poisson Problemi-2}

İkinci Poisson probleminde Dirichlet ve Neumann sinır koşulları beraber bulunmaktadır [20]:

$$
\begin{aligned}
\nabla^{2} \phi(x, y) & =-5,4 x, \\
\frac{\partial \phi}{\partial \mathbf{n}}(x, y) & =0, \quad(x, y) \in \Gamma_{1} \cup \Gamma_{3}, \\
\phi(x, y) & =0,1, \quad(x, y) \in \Gamma_{2}, \\
\phi(x, y) & =1, \quad(x, y) \in \Gamma_{4},
\end{aligned}
$$$$
\Gamma_{1}=\{(x, y): 0 \leq x \leq 1, y=0\}, \Gamma_{2}=\{(x, y): x=1,0 \leq y \leq 1\}
$$$$
\Gamma_{3}=\{(x, y): 0 \leq x \leq 1, y=1\}, \Gamma_{4}=\{(x, y): x=0,0 \leq y \leq 1\}
$$

Eşitlik (13)'ten görüldüğü gibi bu problemde $y=0$ ve $y=1$ olan sınırlarda Neumann sınır koşulları diğer sınırlar için ise Dirichlet sınır koşulları tanımlanmıştır. Bu problemin analitik çözümü Eşitlik (14)’te verilmektedir.

$$
\phi(x, y)=1-0,9 x^{3}
$$

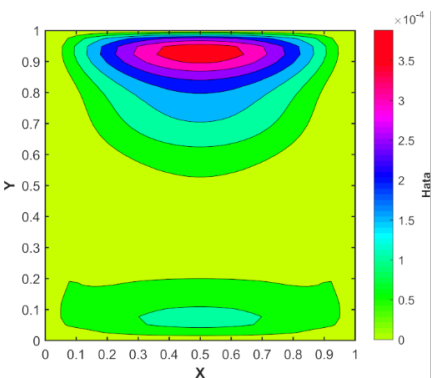

(a)

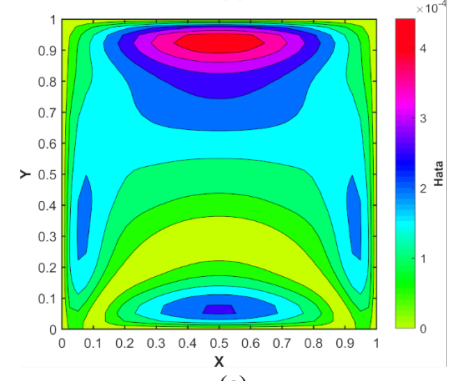

(c)

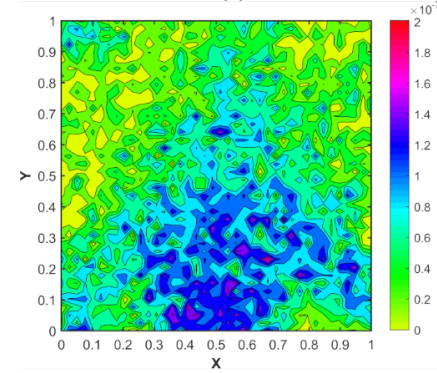

(e)

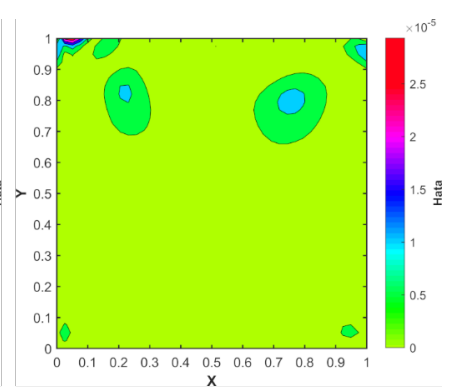

(b)

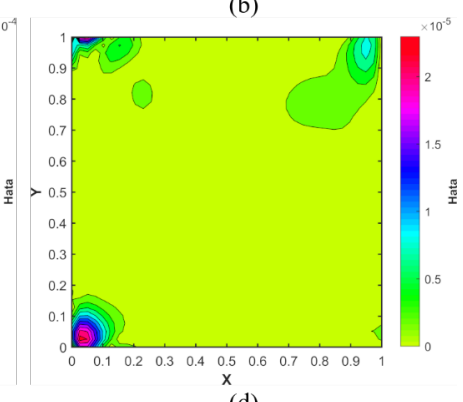

(d)

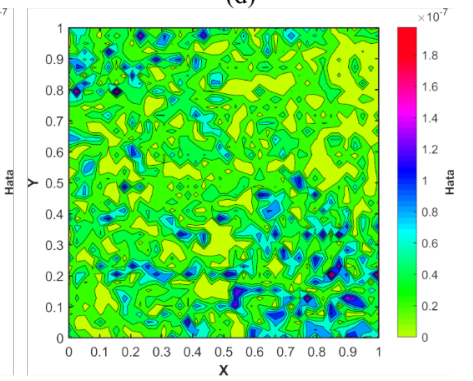

(f)

Şekil 5. 81 nokta sayısı için farklı nokta dağılımında çözüm bölgesindeki hata davranışı: (a) IMQ-Düzgün nokta dağılımı, (b) IMQHalton nokta dağılımı, (c) Gauss-Düzgün nokta dağılımı, (d) Gauss-Halton nokta dağılımı, (e) Sinüs RTF-Düzgün nokta dağıllımı, (f) Sinüs RTF-Halton nokta dağılımı 
IMQ, Gauss ve Sinüs RTF'leri kullanılarak elde edilen karesel hatanın farklı nokta dağılımı ve nokta sayısı için $\epsilon$ parametresine göre değişimi Şekil 6'da verilmiştir. Şekil 3 ve 6'da verilen hata sonuçları kıyaslandığında, en düşük karesel hatanın elde edildiği $\epsilon$ parametresinin, nokta sayısı ve dağılımı dışında probleme ve sınır koşullarına da bağlı olduğu görülmektedir. Benzer duruma daha önce yapılan çalışmalarda da rastlanılmıştır [22]. Bu problemde, nispeten düşük $\epsilon$ değerleri dışında, yüksek $\epsilon$ değerleri için de sayısal kararsızlık bölgesiyle karşılaşılmıştır. Bu duruma Poisson-1 probleminde rastlanılmamıştır. Yüksek $\epsilon$ değerleri için hatada oluşan kararsızlığın Neumann sınır koşullarından kaynaklandığı düşünülmektedir. Bunun dışında, Poisson-1 probleminde olduğu gibi bu problemde de Sinüs-RTF fonksiyonu için hatanın düşük seviyelerde kaldığ $\epsilon$ değerleri geniş bir aralıktadır. Bu özellik, Sinüs-RTF için diğer fonksiyonlarla kıyaslandığında bir avantaj olmaktadır.

Şekil 7'de karesel hatanın sabit $\epsilon$ parametresi için nokta sayısına bağlı olarak değişimi Poisson-2 problemi için gösterilmiştir. RTF'ler için kullanılan $\epsilon$ değerleri Poisson-1 problemiyle aynı olarak alınmıştır. Bu problemde hatanın nokta sayısına göre değişimi Poisson-1 probleminde gözlenen duruma benzerdir. Poisson-1 probleminden farklı olarak, IMQ ve Gauss RTF'ler için nokta sayısı arttıkça hatanın aşağı eğimli bir seyir izlemesi daha belirgindir.

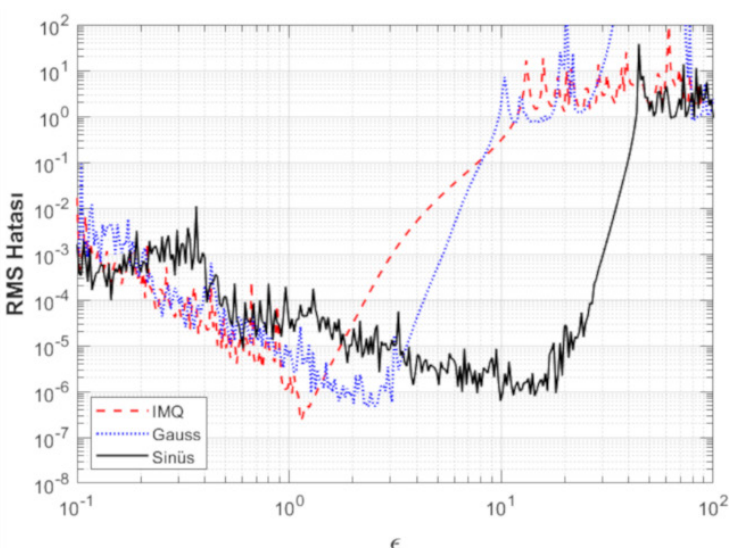

(b)

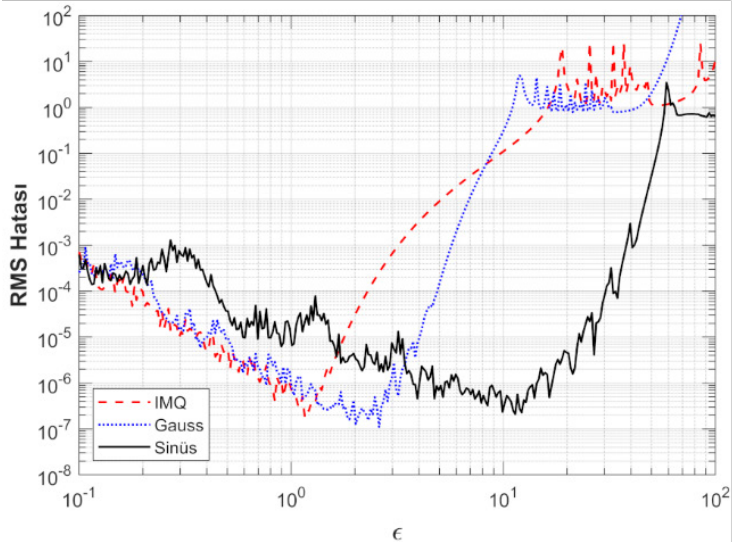

(c)

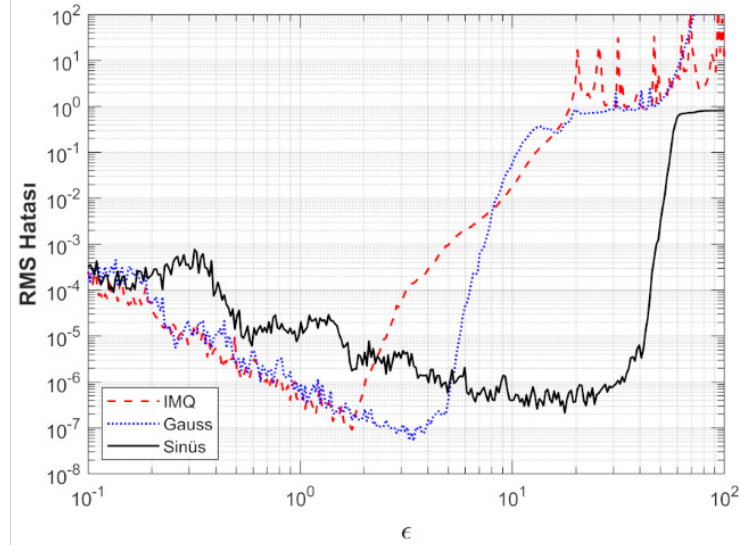

(d)

Şekil 6. Farklı nokta dağılımı ve nokta sayısı için $\epsilon$ parametresine göre karesel hatanın değişimi: (a) 225 nokta düzgün dağılım, (b) 625 nokta düzgün dağılım, (c) 225 nokta Halton dağılımı, (d) 625 nokta Halton dağılımı 


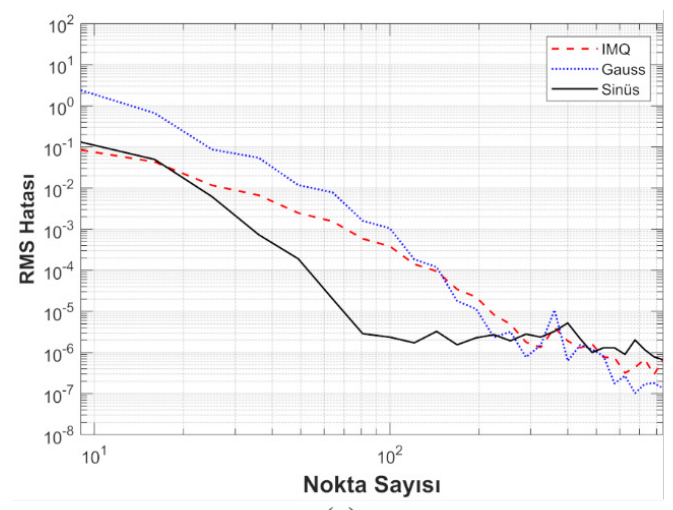

(a)

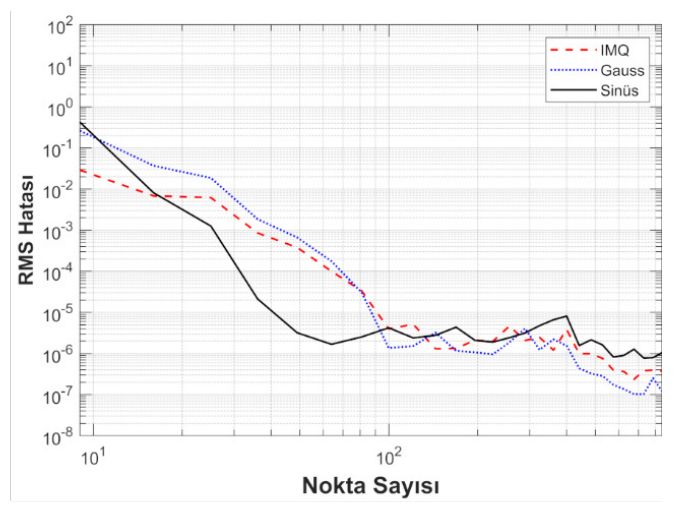

(b)

Şekil 7. Farklı nokta dağılımı ve nokta sayısı için karesel hatanın değişimi: (a) Düzgün nokta dağılımı, (b) Halton nokta dağılımı

Şekil 4 ve 7 incelendiğinde, aynı nokta sayısındaki hata değerlerinin, tüm RTF'ler için Poisson-1 problemine göre yaklaşık 10 kat daha fazla olduğu görülmüştür. Bu durumun daha iyi irdelenebilmesi için 81 nokta için çözüm bölgesindeki hata davranışı Şekil 8'de gösterilmiştir. Düzgün nokta dağılımı durumunda, IMQ ve Gauss RTF'leri için özellikle Neumann sınır koşullarının tanımlandığ $10^{-3}$ mertebelerinde olduğu görülmüsstür. Bu durum, Halton nokta dağılımında ortadan kalkmıştır. Poisson-1 problemine benzer şekilde, hata, düzgün nokta dağılımında kenarlara yakın yüksek değerlerdeyken, Halton nokta dağılımında köşelere yoğunlaşmıştır. Dolayısıyla, köşe ve kenarlarda bulunan nokta sayısının artmasıyla hata belirli bir değere kadar azaltılabilmektedir. Sinüs-RTF sonuçlarına bakıldığında ise, hatanın Halton nokta dağılımı için Poisson-1 problemine benzer şekilde genele yayıldığı görülmüştür. Düzgün nokta dağılımı için ise Dirichlet sınır koşullarının tanımlandığı kenarlara doğru hatanın arttığı gözlemlenmiştir. IMQ, Gauss ve Sinüs-RTF için gözlemlenen bu davranışlar, hatanın Poisson-1 problemine göre daha yüksek mertebelerde olmasina neden olmuştur. Fakat bu davranışların en önemli nedeni, nokta sayısına göre en düşük hatayı veren $\epsilon$ değerinin belirlenerek Şekil 8'in oluşturulmamasıdır. Örnek olarak, Sinüs-RTF'de düzgün nokta dağılımı için $\epsilon=2$ değeri seçilerek analiz yapılması durumunda daha düşük mertebede genele yayılmış bir hata davranışı gözlemlenmiştir.

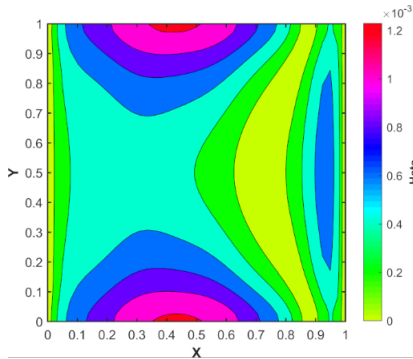

(a)

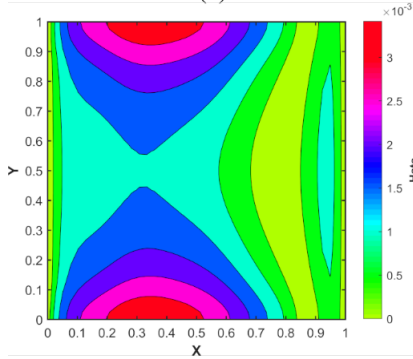

(c)

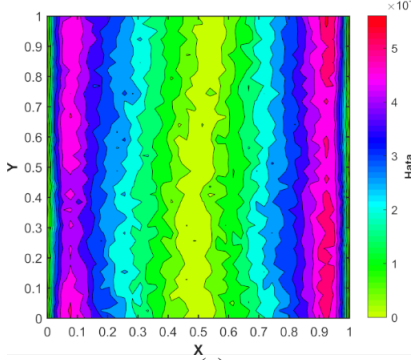

(e)

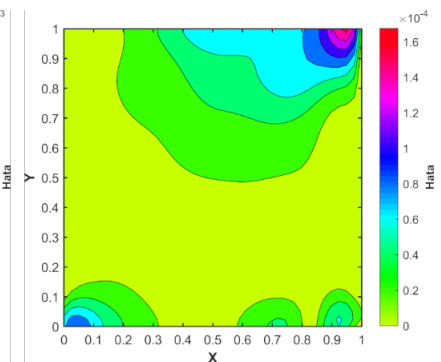

(b)

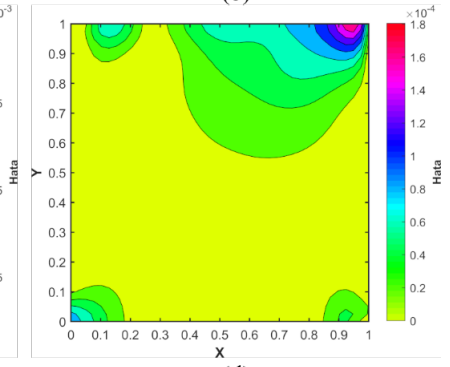

(d)

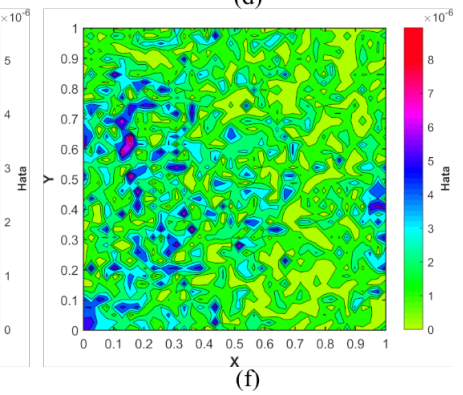

Şekil 8. 81 nokta sayısı için farklı nokta dağılımında çözüm bölgesindeki hata davranışı: (a) IMQ-Düzgün nokta dağılımı, (b) IMQ-Halton nokta dağılımı, (c) Gauss-Düzgün nokta dağılımı,

(d) Gauss-Halton nokta dağılımı, (e) Sinüs RTF-Düzgün nokta dağılımı, (f) Sinüs RTF-Halton nokta dağılımı 


\subsection{Problem 3 - Genel Eliptik Problem (Sızıntı Akışı)}

$a(x, y)=2-x^{2}-y^{2}, b(x, y)=e^{x-y}$ değişkenlerine sahip bu genel eliptik problemde Dirichlet sınır koşulları bulunmaktadır [20]. Problem tanımı Eşitlik (15)'te verilmektedir:

$$
\frac{\partial}{\partial \mathrm{x}}\left[\frac{\mathrm{a}(\mathrm{x}, \mathrm{y}) \partial \phi}{\partial \mathrm{x}}\right]+\frac{\partial}{\partial \mathrm{y}}\left[\frac{\mathrm{b}(\mathrm{x}, \mathrm{y}) \partial \phi}{\partial \mathrm{y}}\right]=-\mathrm{xe}^{\mathrm{x}-\mathrm{y}}(1-\mathrm{x})(3-2 \mathrm{y})+2 \mathrm{y}(1-\mathrm{y})\left(3 \mathrm{x}^{2}+\mathrm{y}^{2}-\mathrm{x}-2\right),
$$

Bu problemin analitik çözümü Eşitlik (16) ile verilmektedir.

$$
\phi(x, y)=x y(1-x)(1-y)
$$

Şekil 9'da genel eliptik problem için karesel hatanın farklı nokta dağılımı ve nokta sayısı için $\epsilon$ parametresine göre değişimi verilmiştir. Bu davranış ilk iki test problemiyle benzerlik göstermektedir. Bu test probleminde, hata değerlerinin $10^{-8}$ mertebelerine kadar düştüğü gözlemlenmiştir.

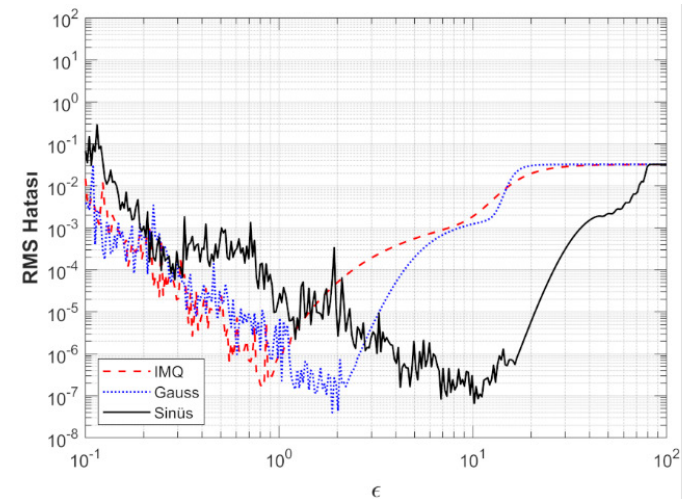

(a)

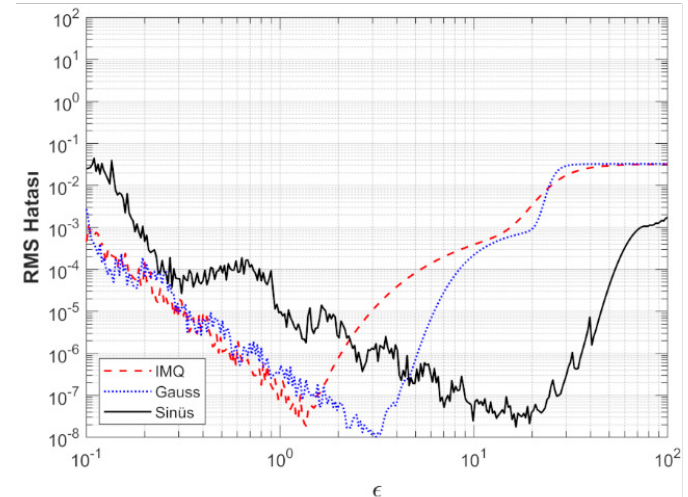

(c)
Fakat burada dikkat edilmesi gereken husus, ilk iki test probleminde analitik çözüm değerleri yaklaşı $10^{-1}$ mertebelerinde iken bu problemde $10^{-2}$ mertebesinde olmasidır. Dolayısıyla hata değerlerinde meydana gelecek yaklaşı 10 katlık azalma göreceli olarak benzer davranışa tekabül etmektedir. Bu problemde Sinüs-RTF, ilk iki test problemine benzer özellikler göstermiştir ve hatanın $10^{-6}$ ' dan daha düşük elde edilebileceği geniş bir $\epsilon$ aralığı gözlemlenmiştir.

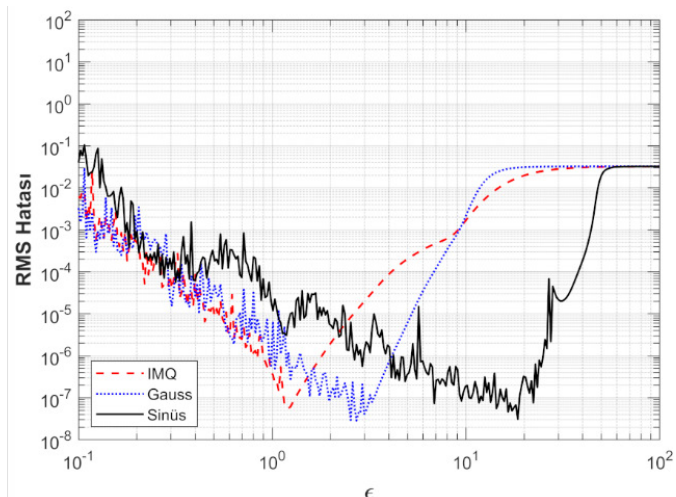

(b)

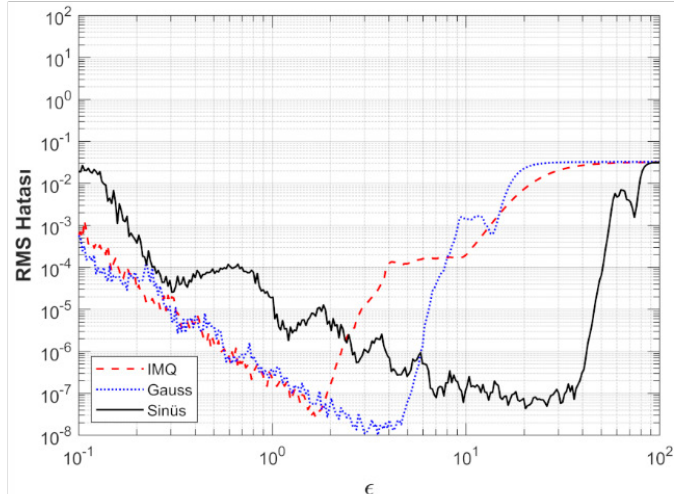

(d)

Şekil 9. Farklı nokta dağılımı ve nokta sayısı için $\epsilon$ parametresine göre karesel hatanın değişimi: (a) 225 nokta düzgün dağılım, (b) 625 nokta düzgün dağılım, (c) 225 nokta Halton dağılımı, (d) 625 nokta Halton dağılımı

Şekil 10'da karesel hatanın sabit $\epsilon$ parametresi için nokta sayısına bağlı olarak değişimi genel eliptik problem için gösterilmiştir. $\epsilon$ değerleri ilk iki problemde olduğu gibi; IMQ, Gauss ve Sinüs RTF'ler için sırasıyla $\epsilon=1, \epsilon=2$ ve $\epsilon=4$ olarak sabit alınmıştır. Genel eliptik problem için karesel hatanın genel davranışı ilk iki test problemiyle benzerdir. Bu problemde, Gauss RTF özellikle düşük nokta sayılarında Poisson-2 problemine kıyasla daha iyi bir performans göstermiştir.

Çözüm bölgesindeki hata davranışı 81 nokta için Şekil 11 'de verilmiştir. İlk iki problemle kıyaslandığında düzgün 
nokta dağılımı durumunda IMQ ve Gauss RTF'leri için hata davranışının farklı olduğu ve hatanın çözüm bölgesi geneli boyunca yüksek olduğu gözlemlenmiştir. Diğer durumlar için elde edilen sonuçlar ise Poisson-1 problemiyle benzerlik göstermektedir. Şekil 5, 8, ve 11 'de verilen hata sonuçları incelendiğinde, hata davranışının IMQ ve Gauss

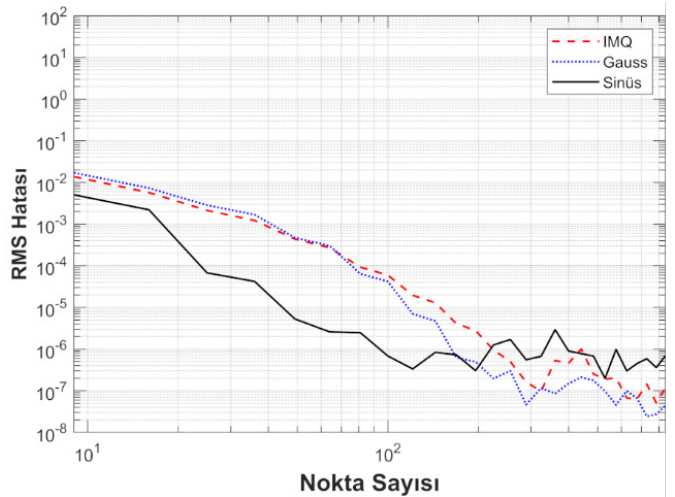

(a)
RTF'leri için problemden ve sınır koşullarından oldukça etkilendiği gözlemlenmiştir. Sinüs RTF için ise hata davranıŞındaki farklılıklar diğer iki RTF için gözlemlenen farklılıklar kadar belirgin olmamakla birlikte hatanın bazı bölgelerde artış eğiliminde olduğu görülmüştür.

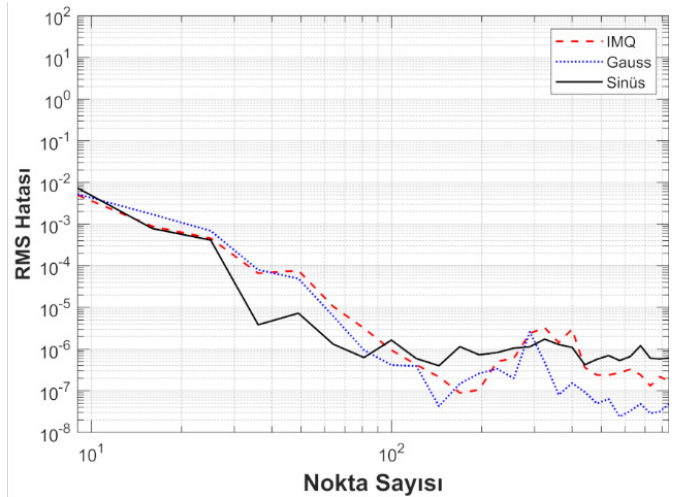

(b)

Şekil 10. Farklı nokta dağılımı ve nokta sayısı için karesel hatanın değişimi: (a) Düzgün nokta dağılımı, (b) Halton nokta dağılımı

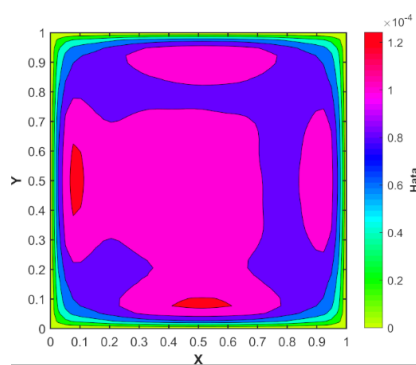

(a)

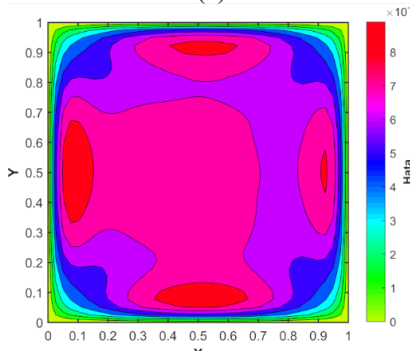

(c)

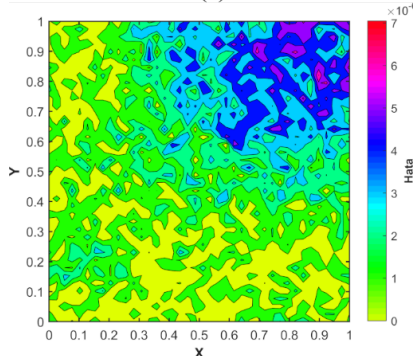

(e)

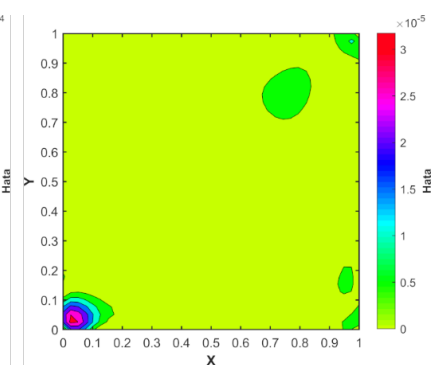

(b)

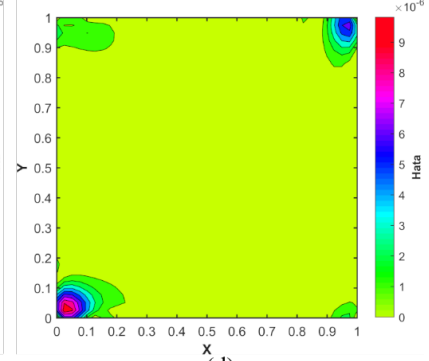

(d)

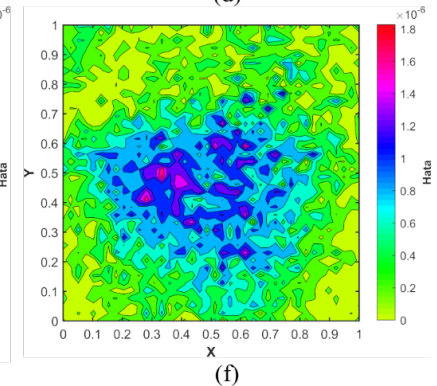

Şekil 11. 81 nokta sayısı için farklı nokta dağılımında çözüm bölgesindeki hata davranışı: (a) IMQ-Düzgün nokta dağılımı, (b) IMQHalton nokta dağılımı, (c) Gauss-Düzgün nokta dağılımı, (d) Gauss-Halton nokta dağılımı, (e) Sinüs RTF-Düzgün nokta dağılımı, (f) Sinüs RTF-Halton nokta dağılımı 


\subsection{Problem 4 - 4. Mertebe Eliptik Problem (Kirchhoff Plaka Eğilmesi)}

Yayılı yük altında eğilmeye maruz kalan homojen,

$$
\begin{aligned}
& \nabla^{4} \phi=\frac{\mathrm{p}}{\mathrm{D}^{\prime}} \\
& \phi(\mathrm{x}, \mathrm{y})=0, \quad(\mathrm{x}, \mathrm{y}) \in \Gamma=\partial \Omega, \\
& M_{n}=-D\left\{v \nabla^{2} \phi(x, y)+(1-v)\left(\cos ^{2} \alpha \frac{\partial^{2} \phi(x, y)}{\partial x^{2}}+\sin ^{2} \alpha \frac{\partial^{2} \phi(x, y)}{\partial y^{2}}+\sin 2 \alpha \frac{\partial^{2} \phi(x, y)}{\partial x \partial y}\right)\right\}=0, \quad(x, y) \in \Gamma=\partial \Omega
\end{aligned}
$$

yönden bağımsız özelliklere sahip basit mesnetli ince plakada meydana gelen deformasyon Eşitlik (17)'deki diferansiyel denklem ile tanımlanmaktadır [23]:
$\mathrm{Bu}$ denklemde $p$ yayılı yükü, $D$ plakanın eğilme rijitliğini, $v$ Poisson's oranını, $\alpha$ ise sınırlarda yüzey normalinin $x$-ekseni ile yapmış olduğu açıyı ifade etmektedir. Problemde sınır koşulları olarak deformasyon ve moment sıfır olarak tanımlanmaktadır. Problemin analitik çözümü (Navier seri çözümü) Eşitlik (18) ile verilmektedir [23].

$$
\phi(x, y)=\frac{16 p}{\pi^{6} D} \sum_{m=1}^{\infty} \sum_{n=1}^{\infty} \frac{\sin (m \pi x) \sin (n \pi y)}{m n\left(m^{2}+n^{2}\right)^{2}}
$$

Eşitlik (18)'de $m$ ve $n$ tek sayıdır. Analitik çözümün elde edilmesinde ilk 100 terim kullanılmıştır. Bu değerin seçilmesinin nedeni, diğer tüm terimlerin toplam etkisinin $10^{-10}$ 'dan daha az olmasidır. Test probleminde $p / D=1$ olarak alınmıştır.

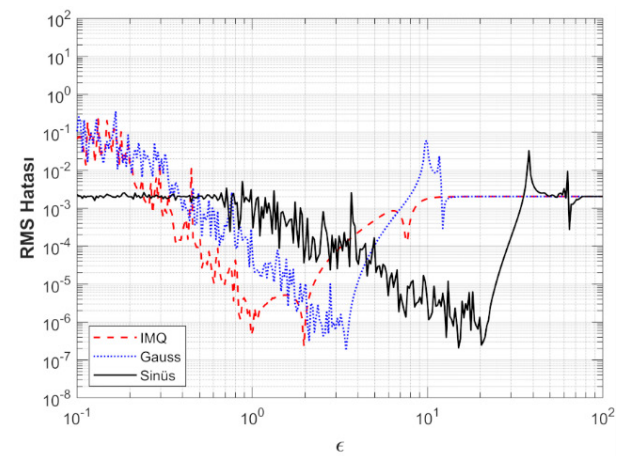

(a)

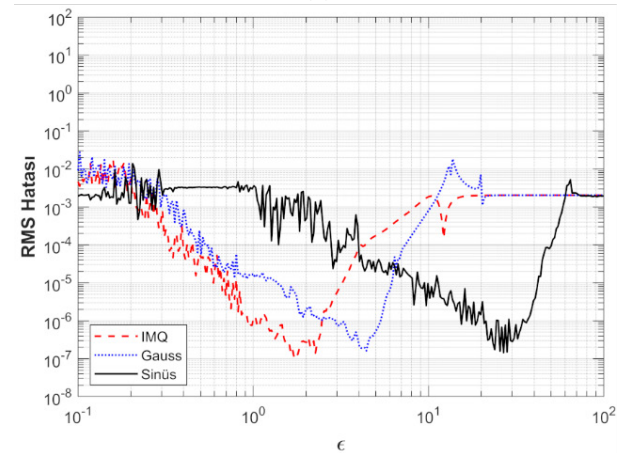

(c)
Şekil 12'de plaka eğilmesi problemi için karesel hatanın farklı nokta dağılımı ve nokta sayısı için $\epsilon$ parametresine göre değişimi verilmiştir. Test edilen diğer problemlerde olduğu gibi IMQ ve Gauss RTF'lerinde hatayı minimum yapan optimum bir $\epsilon$ değeri hem düzgün hem de Halton nokta dağılımı için gözlemlenmiştir. Benzer davranış SinüsRTF için 225 nokta sayısında gözlemlenmiştir. Nokta sayıs1 625 olduğunda ise, diğer test problemlerinde olduğu gibi Sinüs-RTF için hatanın belirli bir değerden düşük olduğu bir $\epsilon$ aralığ 1 ortaya çıkmıştır. 625 nokta sayısı ve Halton nokta dağılımında tüm RTF'ler için minimum hata değerleri diğer test problemlerine kıyasla artmıştır fakat bu oran Sinüs-RTF için daha belirgindir. Sonuçların daha iyi değerlendirilebilmesi için minimum karesel hata ve bu hatanın elde edildiği $\epsilon$ parametresi değerleri tüm RTF'ler için Tablo 2'de verilmektedir.

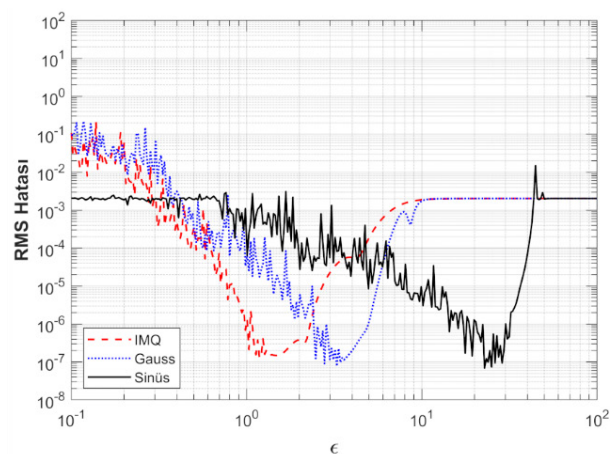

(b)

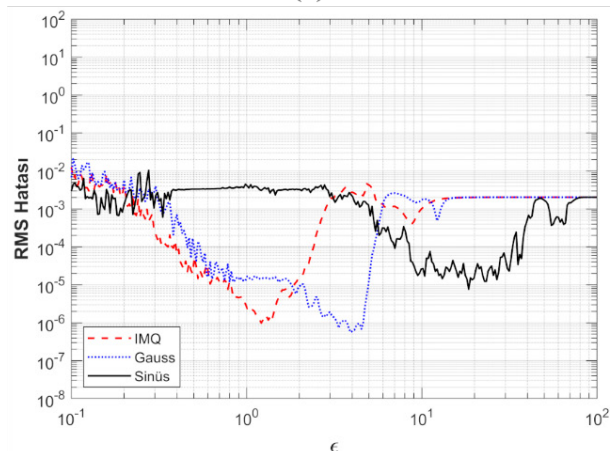

(d)

Şekil 12. Farklı nokta dağılımı ve nokta sayısı için $\epsilon$ parametresine göre karesel hatanın değişimi: (a) 225 nokta düzgün dağılım, (b) 625 nokta düzgün dağılım, (c) 225 nokta Halton dağılımı, (d) 625 nokta Halton dağılımı 
Tablo 2. Minimum karesel hatanın elde edildiği $\epsilon$ değerleri

\begin{tabular}{ccccc|ccccccccc}
\hline İsim & \multicolumn{4}{c}{ IMQ } & \multicolumn{1}{c}{ Gauss } & \multicolumn{3}{c}{ Sinüs } \\
\hline Nokta sayısı ve dağılıııı & 225 & 625 & 225 & 625 & 225 & 625 & 225 & 625 & 225 & 625 & 225 & 625 \\
(H-Halton, D-Düzgün) & $\mathrm{D}$ & $\mathrm{D}$ & $\mathrm{H}$ & $\mathrm{H}$ & $\mathrm{D}$ & $\mathrm{D}$ & $\mathrm{H}$ & $\mathrm{H}$ & $\mathrm{D}$ & $\mathrm{D}$ & $\mathrm{H}$ & $\mathrm{H}$ \\
\hline Minimum hata $\left(\times 10^{-7}\right)$ & 2.29 & 1.00 & 1.05 & 12.11 & 0.98 & 1.95 & 0.66 & 6.71 & 0.47 & 1.43 & 0.75 & 74.29 \\
$\epsilon$ & 1.97 & 1.71 & 1.11 & 1.18 & 3.43 & 4.22 & 3.06 & 4.52 & 20.78 & 22.28 & 22.80 & 18.52 \\
\hline
\end{tabular}

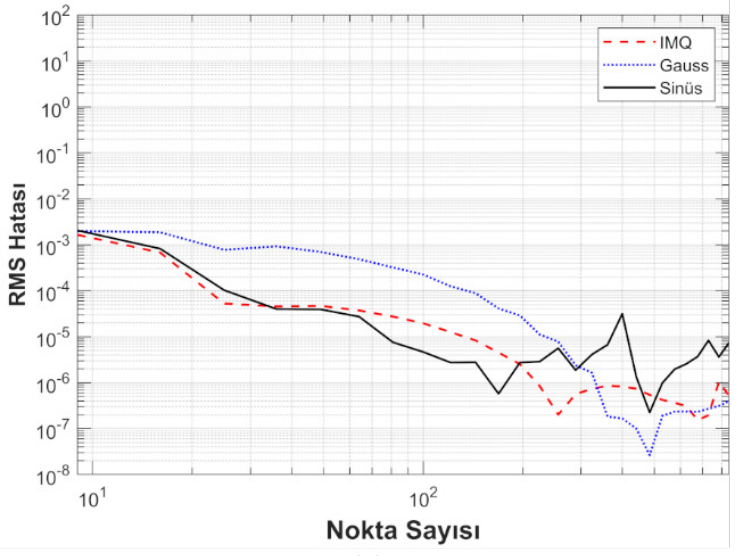

(a)

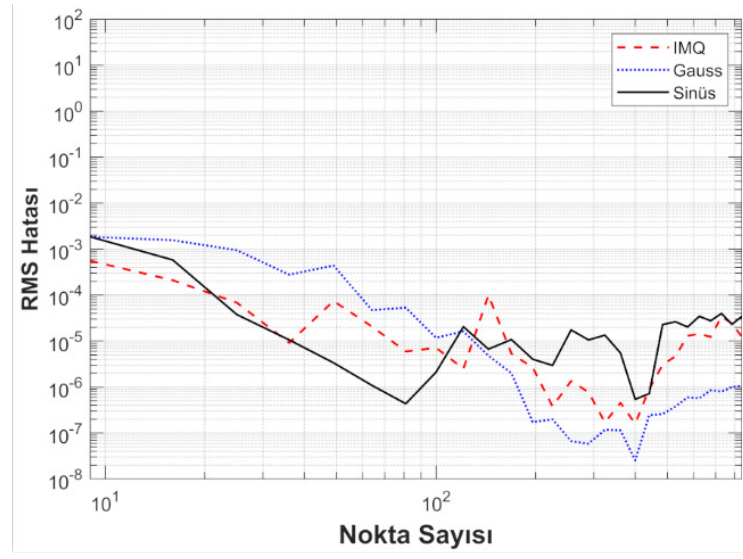

(b)

Şekil 13. Farklı nokta dağılımı ve nokta sayısı için karesel hatanın değişimi: (a) Düzgün nokta dağılımı, (b) Halton nokta dağılımı

Karesel hatanın sabit $\epsilon$ parametresi için nokta sayısına bağlı olarak değişimi 4. mertebe eliptik problem için Şekil 13 'te gösterilmiştir. Diğer problemlerden farklı olarak, $\epsilon$ değerleri IMQ, Gauss ve Sinüs RTF'ler için sırasıyla $\epsilon=2$, $\epsilon=4$ ve $\epsilon=10$ olarak alınmıştır. Karesel hatanın genel davranışı, Sinüs ve IMQ RTF'leri için benzerlik göstermektedir. Gauss RTF ise özellikle fazla nokta sayılarında daha iyi performans sergilemektedir. Nokta sayısı belirli bir değeri aştı̆̆ında diğer test problemlerinde olduğu gibi hata davranışında kararsızlıklar oluşmuştur. Bu kararsızlıklar Halton nokta dağılımı için daha belirgindir.

Çözüm bölgesindeki hata davranışı 81 nokta için Şekil 14 'te verilmiştir. Bu problemin Eşitlik (18)'de verilen analitik çözümü eksenel simetriktir. Düzgün nokta dağılımı için Gauss ve IMQ RTF'leri için yaklaşık çözümün de simetrik olduğu hata sonuçlarından anlaşılmaktadır. Fakat Halton nokta dağılımında, noktaların düzgün olmayan dağıl1mından dolayı bu davranış bozulmaktadır. Sinüs RTF'de ise fonksiyonun harmonik davranışından dolayı düzgün nokta dağılımı olduğu durumda dahi tam simetrik sonuç elde edilememiştir. Diğer test problemlerinde, bu problemde tüm RBF'ler için ortaya çıkan genel hata davranışı gözlemlenmemiştir. Ayrıca, bu test probleminde Halton nokta dağılımı düzgün nokta dağılımına göre daha düşük hata oluşmasını sağlamıştır.

\subsection{Sinüs-RTF Sonuçları ve Tartışmaları}

Şekil 3, 6, 9 ve 12 'de verilen sonuçlar incelendiğinde, Sinüs-RTF kullanıldığı durumlarda hatanın minimum olduğu bir $\epsilon$ aralığının olduğu ve bu aralığın problemin türüne, nokta dağılımına ve nokta sayısına göre farklılık gösterdiği görülmüştür. Örnek olarak, 2. mertebe diferansiyel denklem içeren ilk üç test probleminde düzgün nokta dağılımı ve 225 nokta sayısı için hatanın minimum olduğu aralık yaklaşık olarak $4<\epsilon<11$ olarak değişirken, Halton nokta dağılımı durumunda aralık $4<\epsilon<20$ olarak gözlemlenmiştir. Nokta sayısı $625^{\prime}$ e çıktığında ise bu aralığın özellikle üst sınırının arttığı görülmüştür. Dolayısıyla nokta sayısı ile $\epsilon$ üst sınırı arasında bir ilişkiden söz edilebilir. 4. mertebe diferansiyel denklem içeren son test probleminde ise 225 nokta sayısı için düzgün ve Halton nokta dağılımı durumunda bu aralık sırasıyla $7<\epsilon<23$ ve $14<\epsilon<32$ olarak değişmiştir. Her ne kadar sınır koşullarında 1. mertebe terimler içeren üçüncü test probleminde ilk iki test problemine kıyasla $\epsilon$ aralığında ufak farklılıklar olsa da, bu farklılıklar 2. mertebe terimleri içeren son test probleminde belirgin şekilde ortaya çıkmaktadır.

Test edilen problemlerde Sinüs-RTF'nin farklı nokta sayılarında ve $\epsilon$ değerlerinde nasıl bir davranış gösterdiği Şekil 15'te gösterilmektedir. 2. mertebe problemlerde geniş bir $\epsilon$ aralığında ve düşük nokta sayılarında düşük hata mertebelerine erişilebilmiştir. Düzgün nokta dağılımında 50, Halton nokta dağılımında ise 40 nokta sayısından 
başlayarak nokta sayısındaki artış ile orantılı olarak genişleyen bir $\epsilon$ aralığında düşük hatalar elde edilebilmiştir. Plaka eğilmesi probleminde ise optimum $\epsilon$ aralığının daha dar olduğu gözlemlenmiştir. Özellikle Halton nokta dağılımında nokta sayısının 500'ün üzerine çıkmasıyla sayısal kararsızlıklar nedeniyle diğer problemlerde hatanın düşük olduğu $4<\epsilon<40$ aralığında daha yüksek hataların oluştuğu görülmüştür. Bu davranışa neden olan en önemli etken 4. mertebe problemlerde türevlerin daha fazla sayıda terime sahip olması ve çözümün bu terimlerin hassas olarak elde edilmesine yakından bağlı olmasıdır.

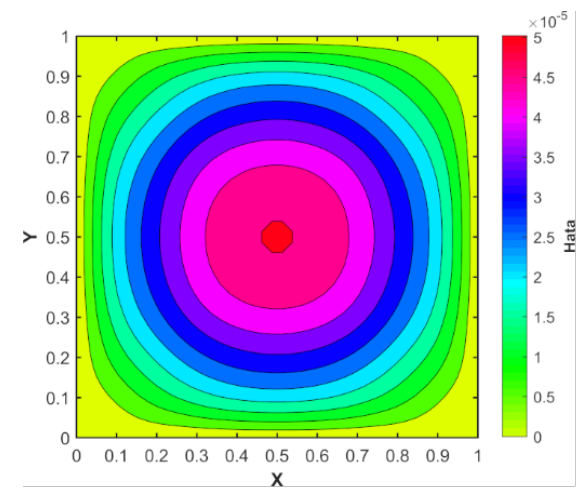

(a)

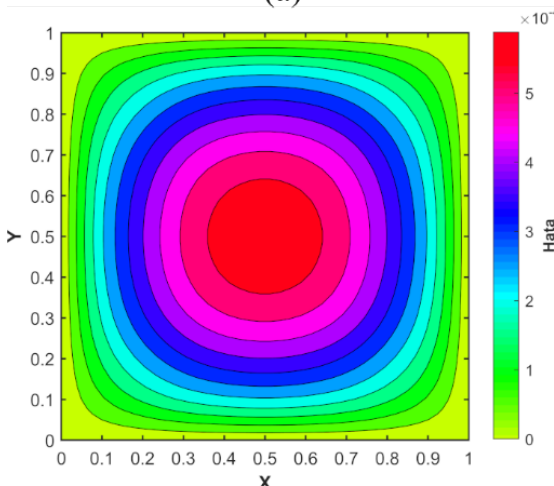

(c)

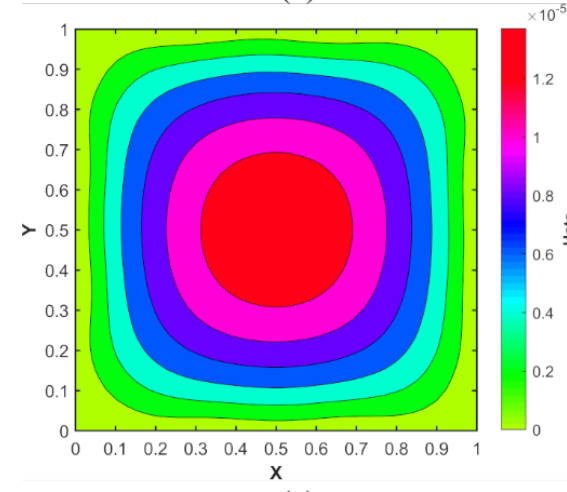

(e)

\section{SONUÇLAR}

Yapılan çalışmada ağsız yöntemlerin bir kolu olan radyal özelliğe sahip temel fonksiyon yöntemi için yeni bir fonksiyon önerilmiştir. Önerilen fonksiyon dört farklı problemde test edilmiştir. Elde edilen sonuçlar, önerilen Sinüs-RTF'nin, IMQ ve Gauss RTF'ye göre daha az nokta sayılarında daha düşük hata değerlerine ulaşabildiğini göstermiştir. Ayrıca, nokta sayısının artmasıyla kullanılabilecek optimum $\in$ aralığının genişlediği ve nokta sayısı ile $\epsilon$ üst değerinin ilişkili olduğu görülmüştür. Dolayısıyla, önerilen Sinüs-RTF'nin ağsız yöntemlerde, IMQ ve Gauss RTF'ye kıyasla bir alternatif olarak kullanılabileceği gösterilmiştir.

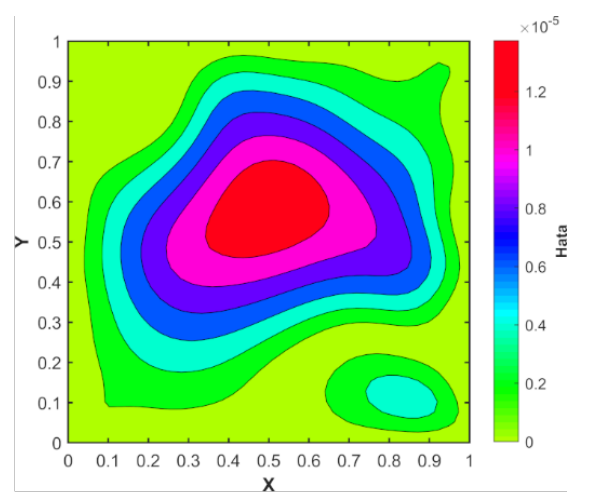

(b)

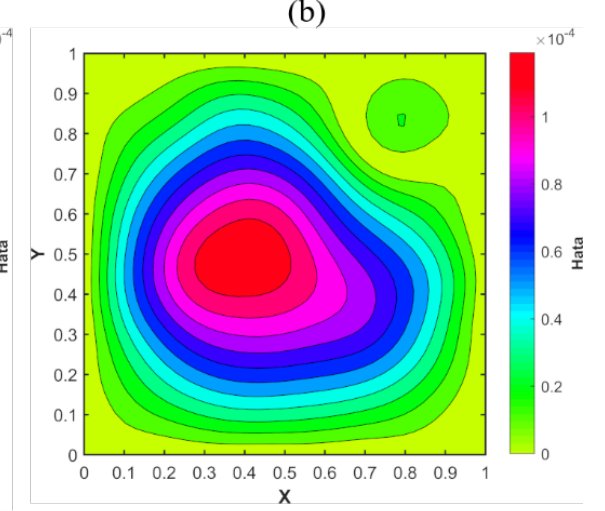

(d)

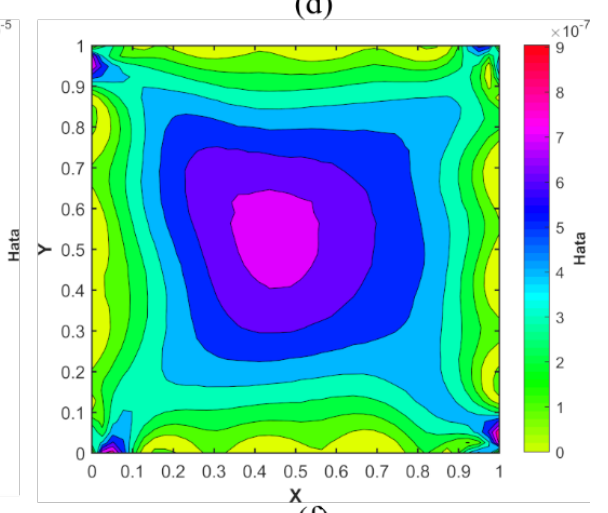

(f)

Şekil 14. 81 nokta sayısı için farklı nokta dağılımında çözüm bölgesindeki hata davranış1: (a) IMQ-Düzgün nokta dağ1lımı, (b) IMQHalton nokta dağılımı, (c) Gauss-Düzgün nokta dağılımı, (d) Gauss-Halton nokta dağılımı, (e) Sinüs RTF-Düzgün nokta dağılımı, (f) Sinüs RTF-Halton nokta dağılımı 


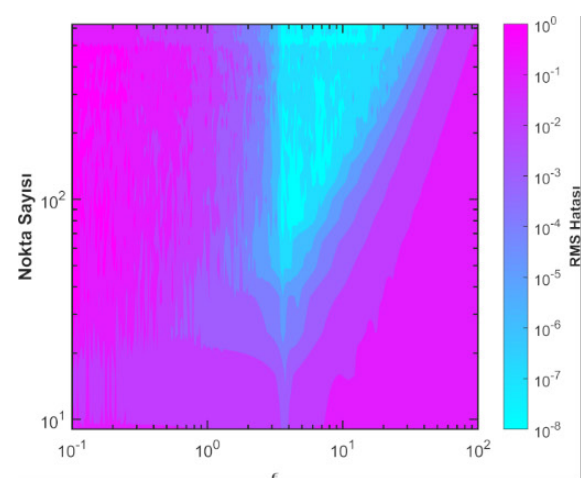

(a)

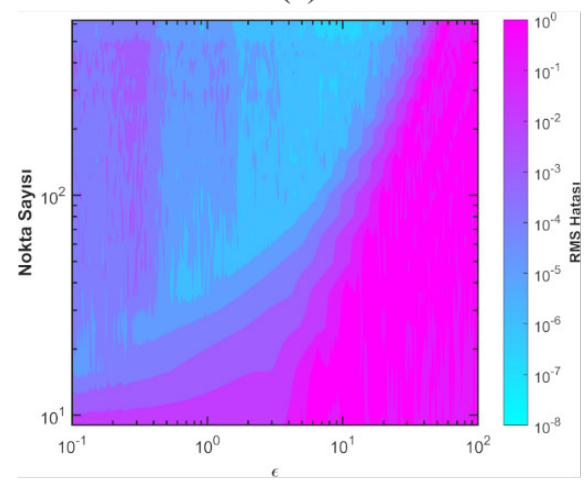

(c)

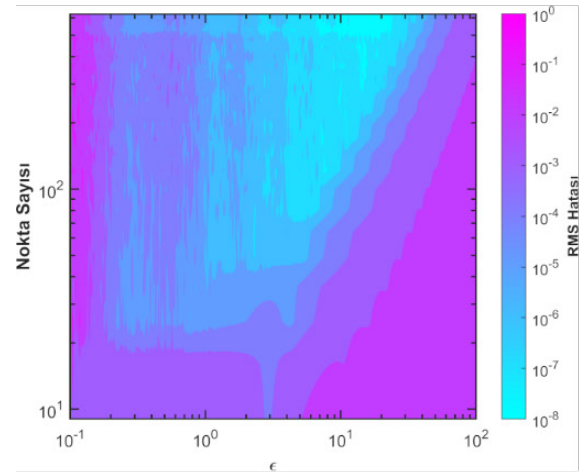

(e)

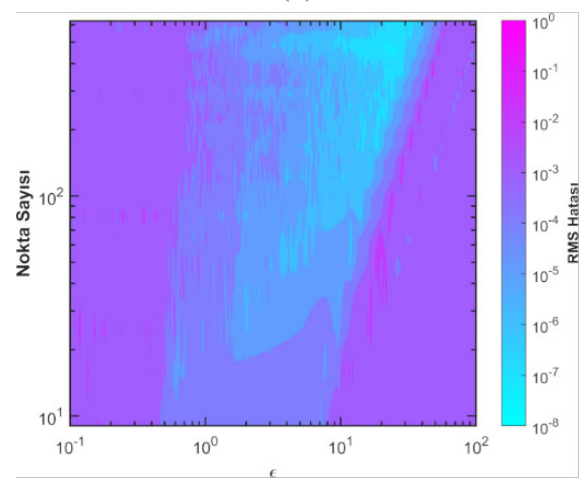

(g)

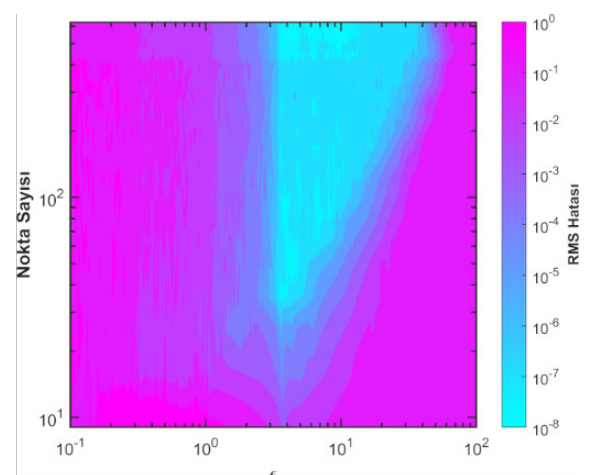

(b)

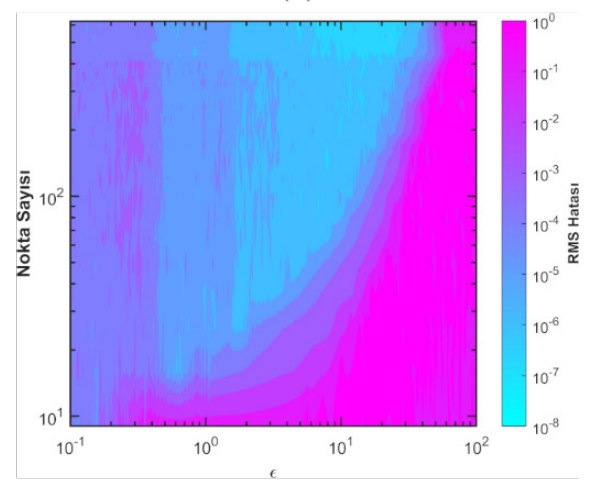

(d)

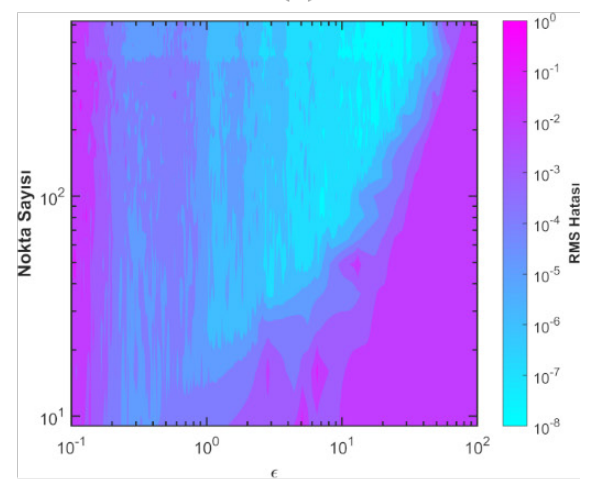

(f)

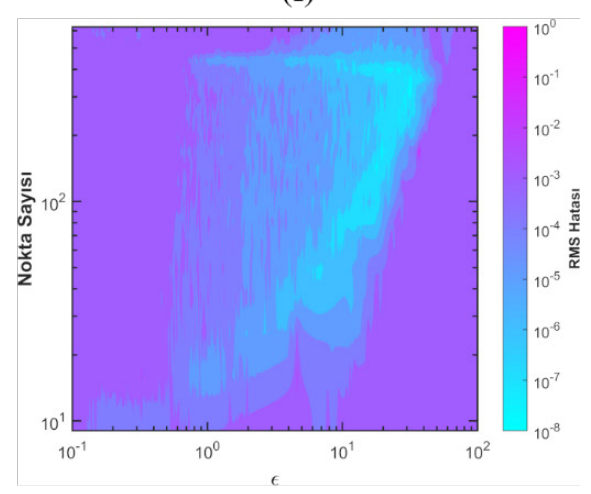

(h)

Şekil 15. Farklı nokta dağılımı, nokta sayısı ve $\epsilon$ parametresine göre Sinüs-RTF için karesel hatanın değişimi: (a) Poisson 1-Düzgün nokta dağılımı, (b) Poisson 1-Halton nokta dağılımı, (c) Poisson 2-Düzgün nokta dağılımı, (d) Poisson 2-Halton nokta dağılımı, (e) Problem 3-Düzgün nokta dağılımı, (f) Problem 3-Halton nokta dağılımı, (g) Problem 4-Düzgün nokta dağılımı, (h) Problem 4-Halton nokta dağılımı 


\section{KAYNAKLAR}

[1] Altınkaynak, A., Gupta, M., Spalding, M. A., \& Crabtree, S. L. (2011). Melting in a Single Screw Extruder: Experiments and 3D Finite Element Simulations. International Polymer Processing, 26(2), 182-196.

[2] Uygun, M., \& Kirkköprü, K. (2011). Kat1 yakıtlı roket motorlarında daimi olmayan akışların ikili zaman adımlaması yöntemi ile sayısal benzetimi. ITÜDERGISII/d, 8(2).

[3] Kığgl1, H. N. (2006). Tünel Üst Yapı Etkileşim Problemlerinin Sinır Elemanlar Yöntemiyle İncelenmesi. İTÜ Fen Bilimleri Enstitüsü.

[4] Rodrigues, D., Belinha, J., Pires, F., Dinis, L., \& Jorge, R. N. (2018). Homogenization technique for heterogeneous composite materials using meshless methods. Engineering Analysis with Boundary Elements, 92, 73-89.

[5] Fasshauer, G., \& McCourt, M. (2015). Kernel-based approximation methods using Matlab (Vol. 19): World Scientific Publishing Company.

[6] Kansa, E. J. (1990b). Multiquadrics - A scattered data approximation scheme with applications to computational fluid-dynamics-II solutions to parabolic, hyperbolic and elliptic partial differential equations. Computers \& Mathematics with Applications, 19(8), 147-161.

[7] Kansa, E. J. (1990a). Multiquadrics - A scattered data approximation scheme with applications to computational fluid-dynamics - I surface approximations and partial derivative estimates. Computers \& Mathematics with Applications, 19(8), 127-145.

[8] Fornberg, B., \& Flyer, N. (2015b). Solving PDEs with radial basis functions. Acta Numerica, 24, 215-258.

[9] Fornberg, B., \& Flyer, N. (2005). Accuracy of radial basis function interpolation and derivative approximations on 1-D infinite grids. Advances in Computational Mathematics, 23(1-2), 5-20.

[10] Fasshauer, G. E. (2007). Meshfree approximation methods with MATLAB (Vol. 6): World Scientific.

[11] Fornberg, B., \& Wright, G. (2004). Stable computation of multiquadric interpolants for all values of the shape parameter. Computers \& Mathematics with Applications, 48(5-6), 853-867.

[12] Larsson, E., Lehto, E., Heryudono, A., \& Fornberg, B. (2013). Stable computation of differentiation matrices and scattered node stencils based on Gaussian radial basis functions. SIAM Journal on Scientific Computing, 35(4), A2096-A2119.

[13] Fasshauer, G. E. (1999). Solving differential equations with radial basis functions: multilevel methods and smoothing. Advances in Computational Mathematics, 11(2-3), 139-159.

[14] Chou, C., Sun, C., Young, D., Sladek, J., \& Sladek, V. (2015). Extrapolated local radial basis function collocation method for shallow water problems. Engineering Analysis with Boundary Elements, 50, 275-290.

[15] Farahani, B. V., Berardo, J., Belinha, J., Ferreira, A., Tavares, P. J., \& Moreira, P. (2017). On the optimal shape parameters of distinct versions of RBF meshless methods for the bending analysis of plates. Engineering Analysis with Boundary Elements, 84, 77-86.

[16] Xia, C.-c., Jiang, T.-t., \& Chen, W.-f. (2016). Particle Swarm Optimization of Aerodynamic Shapes With Nonuniform Shape Parameter-Based Radial Basis Function. Journal of Aerospace Engineering, 30(3), 04016089.

[17] Biazar, J., \& Hosami, M. (2017). An interval for the shape parameter in radial basis function approximation. Applied Mathematics and Computation, 315, 131-149.

[18] Larsson, E., \& Fornberg, B. (2003). A numerical study of some radial basis function based solution methods for elliptic PDEs. Computers \& Mathematics with Applications, 46(5), 891-902.

[19] Fornberg, B., \& Flyer, N. (2015a). A primer on radial basis functions with applications to the geosciences: SIAM.

[20] Li, J., Cheng, A. H.-D., \& Chen, C.-S. (2003). A comparison of efficiency and error convergence of multiquadric collocation method and finite element method. Engineering Analysis with Boundary Elements, 27(3), 251-257.

[21] Golbabai, A., Mohebianfar, E., \& Rabiei, H. (2015). On the new variable shape parameter strategies for radial basis functions. Computational and Applied Mathematics, 34(2), 691704.

[22] Schaback, R. (2009). Solving the Laplace equation by meshless collocation using harmonic kernels. Advances in Computational Mathematics, 31(4), 457.

[23] Leitao, V. M. (2001). A meshless method for Kirchhoff plate bending problems. International Journal for Numerical Methods in Engineering, 52(10), 1107-1130. 